\title{
A New Comparison Of Active Learning Strategies To Traditional Lectures For Teaching College Astronomy
}

Michael C. LoPresto, Ph.D., Henry Ford College, and University of Michigan, USA

Timothy F. Slater, Ph.D., University of Wyoming, USA

\begin{abstract}
Although traditional lectures are still the dominant form of undergraduate instruction, there have been relatively few studies comparing various learner-centered and active learning teaching strategies to one another in order to guide professors in making informed instructional decisions. To study the impact of different active learning approaches, pre-test to posttest learning gains for students receiving instruction on introductory astronomy solar system topics through a combination of collaborative learning activities and formative assessment-driven activities were compared to the gains of students being taught the same topics by traditional lectures only. After traditional lectures, students improved from a pre-test score of $42 \%(n=144)$ to $49 \%(n=49)$. After lecture tutorials and classroom voting response systems improvement was to $73 \%(n=72)$ Using a multiple-group comparison approach, similar earning gains were also observed when using visual-assessment and tutorial activities. Moreover, data from a Likert-style attitude survey of 264 undergraduates showed that, although they did not report a clear preference for one instructional mode over the other, the majority of students believed that the active and collaborative nature of the activities helped them learn. The results of this study add weight to the notion that most modern pedagogies are superior to traditional lecture, and that although the relative impacts of particular pedagogies are mostly indistinguishable from one another, they are all are better than traditional lecture alone.
\end{abstract}

Keywords: Astronomy Education Research; Active Learning; Lecture-Tutorials; Visual-Assessments; Formative Assessment

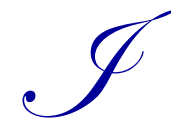

$\mathrm{n}$ recent years, there has been increased attention to improving instruction in undergraduate, general education courses across higher education institutions. Considerable criticism, summarized by Bok (2009) and other higher education scholars like him, is being leveled at colleges and universities for not providing effective instruction that transforms students into productive members of society who have critical thinking skills across a wide variety of disciplines. Much of the energy toward reforming introductory courses is specifically directed toward the domains of science, technology, engineering and mathematics, hereafter referred to as STEM. Many of the calls for improved STEM teaching at the undergraduate level are the result of national concerns about insufficient diversity in the STEM career pipelines or national declines in global technological competitiveness, and are described at length elsewhere (NAP, 2007).

Although traditional lectures are still the dominant form of undergraduate instruction in most first- and second-year college courses, STEM professors are becoming ever more open to considering changing long-held traditional lecture practices to instead try some of the many active-learning and learner-centered instructional strategies available (Nielsen, 2011). Learner-centered strategies are certainly not new, and there has long been an abundance of education research supporting the effectiveness of such approaches; however, active learning approaches are still not widespread across the United States (Adams \& Slater, 2002; Bonwell \& Eison, 1991; Singer, Nielsen \& Schweingruber, 2012).

Student-centered learning environments are most often characterized as students being active participants who are intellectually engaged in course topics rather than passive listeners. The broad notions of active learning are most often framed from the principles and learning environments described in the widely recognized and oft cited National Academy of Science reports on the topic, known generally as How People Learn (Bransford, Brown \& Cocking, 2000; 
Donovan \& Bransford, 2005). The recommendations from these reports are organized into three overarching teaching and learning principles: (i) students come to classrooms with existing understanding that is based largely on their experience that must be engaged before new learning can occur; (ii) to be readily accessed then understood, factual knowledge must be organized into conceptual frameworks; and (iii) instruction should be based on attempting to have students take control of their own learning.

The authors of How People Learn emphasize that the most effective faculty have designed well-defined learning goals and strive to help students frequently monitor their own progress. These principles seem to be required elements in order for active learning to be effective and preferred by students. The authors of these research-summarizing reports also describe the importance of creating both learner-centered environments where instruction begins with attention being paid to what students know, the skills they possess and their attitudes and beliefs, and assessment-centered environments where instructors seek frequent feedback on what students know and what has and has not been learned prior to traditional testing.

Unquestionably, there are numerous ways a professor might imagine realizing the recommendations and guidelines presented in How People Learn. For implementing these ideas in college STEM courses specifically, the most notable authors are Kober (2015), who provides numerous illustrative case studies, and Fairweather (2008), who provides a comprehensive list connecting research evidence to specific instructional approaches. At the same time, many studies, some of which are cited below, repeatedly show that traditional lectures are ineffective when compared to learnercentered teaching. Although the results are compelling, the majority of these studies do not clearly distinguish which of the various learner-centered teaching approaches are most effective. In effect, professors who are motivated to change to learner-centered teaching are left struggling with reasonable questions about which of the available learner centered teaching strategies advocated by education reformers they should use. In an effort to provide guidance to inthe-trenches professors teaching introductory STEM classes, this study is motivated by the overarching question of what is the measurable impact of different active learning approaches in the context of an introductory astronomy survey course for non-science majoring undergraduate students.

\section{BACKGROUND \& CONTEXT}

Summarized by the National Research Council, Singer, Nielsen and Schweingruber (2012) eloquently demonstrate that discipline-based science education consistently shows that college students' conceptual learning gains are higher when instruction focuses on engaging students actively rather than when students simply listen and take notes in a traditional instructor-centered, information-download lectures. Although there are many ways to enact this broad term of active learning, two specific domains of education research with longstanding research records confirming this are: (i) collaborative learning groups and (ii) frequent assessments of learning.

\section{Collaborative Learning and Lecture-Tutorials for Introductory Astronomy}

Perhaps the longest history of education research studies are those that center on the effectiveness of learning when working in student groups. Consistently, we see that students working in collaborative learning groups not only learn more, they also have longer retention and experience more enjoyment of the learning process. (Chickering \& Gamson 1999; Lasry, Mazur, \& Watkins, 2008, among many others). By being told a smaller amount of information through lecture and instead allocating more instructional time to exploring the more nuanced ideas of a concept, research suggests that actual process of and responsibility for learning being moved from the professor to the student encourages students to be more independent and effective in their learning. In other words, when students explore and handle data on their own, they relate it to their own experiences, thus becoming the scientists themselves (Weimer, 2002).

At its core, collaborative learning involves students, often of varying levels of skill and achievement, working together in small groups and being responsible for each other's learning with the purpose of completing a task or achieving a goal. Student problem-solving skills can improve, often due to being better able to visualize a problem when presented with another's perspective or interpretation. A result of this greater engagement caused by an increased responsibility for not only their own, but the group's learning can result in both higher achievement and retention. In more than one study, students who worked in groups showed significantly greater gains on conceptual questions than students who 
worked as individuals and there were many more positive than negative comments about working in groups (Adams \& Slater, 2002; Gokhale, 1995).

In the domain of the introductory astronomy survey course college students often take to fulfill a general education distribution requirement common among most US universities teaching, one of the most widespread active learning instructional pedagogies that leverages collaborative learning is arguably lecture-tutorials which is used by more than 30,000 students each year (Prather, Slater, Bailey, Jones, \& Dostal, 2005). Funded by several NSF awards, Lecturetutorials (Prather, Slater, Adams, \& Brissenden, 2012) are collaborative learning activities that have become very popular for use in general education introductory astronomy courses (Prather, Rudolph, Brissenden, \& Schlingman, 2009). Essentially short student worksheets are carefully designed for students to work with and discover the conceptual power of scientific models for themselves rather than being lectured to about them. The tutorials consist of a series of short questions that build on one another, including questions addressing common misconceptions. They were originally designed for use in large lecture-hall sections with hundreds of students, but can be used, perhaps even more effectively, with smaller sized classes.

The recommended method Prather and Brissenden (2009) advocate to use of lecture-tutorials is directly aligned with the Donovan and Bransford's (2005) recommended guidelines for effective instruction described earlier. Instruction using lecture-tutorials begins with a short introductory lecture on the topic to set the stage for the lecture-tutorial. Next, students complete the lecture-tutorials worksheet in small collaborative learning groups over a several minutes long periods during class with the instructor circulating around the classroom to answer students' questions. After completion of the tutorial, a short wrap-up lecture or debriefing is recommended.

\section{Using Formative Assessment for Teaching in Introductory Astronomy}

Finding ways to help professors know when students do or do not yet understand an idea as well as helping students metacognitively recognize when they've learned an idea are fully in line with Donovan and Bransford's (2005) recommended guidelines for effective instruction. As for designing learning activities, a focus on assessment can drive student learning by attempting improvement while instruction is still in progress. Brissenden, Slater, and Mathieu (2001) argue that when posed prior to instruction as a diagnostic, students can see what they will be learning or what they will be expected to know. This also gives instructors an idea of what students initially know about a topic, allowing for modifications to the instructional plan. As opposed to only using assessment to summarize a learner's achievement at the end of an instructional unit, assessment repeatedly used in a formative way during instruction gives both students and instructor feedback on whether student knowledge needs to be added to or revised while there is still the opportunity to do so (Bransford, Brown \& Cocking, 2000; Mazur, 2009; Weimer, 2002). Overall, experienced instructors know that it is often necessary to adjust instructional plans in response to formative assessment (Keeley \& Sneider, 2012).

The most effective formative assessments used in the service of improved student achievement seem to be those that are low stakes, and do not drastically impact students' grades. This seems to reduce student anxiety and more often results in a more honest evaluation of what students do and do not know (Weimer, 2002). If discussions are not formally evaluated, more students are likely participate, experiencing greater benefit. James, Barbieri, and Garcia (2008) found that that when involved in high-stake discussion for points or a grade, students are more likely to defer to the member perceived by others is a group as the 'smartest' or 'best' rather than take metacogntive risks needed for improved comprehension.

In the domain of astronomy teaching, the most dominant instructional strategy to give students rapid feedback on their learning progress is widely known as think-pair-share or "clickers" (Green 2003; Mazur 1997) and has been embraced by many for learner-centered teaching instructors other STEM disciplines (Duncan 2006, 2007; Prather \& Brissenden 2009). In its most common astronomy teaching manifestation, a multiple-choice question is projected on a screen, a vote is taken from students before they have had the opportunity to review their notes or talk to a peer. If less than two-thirds to three-fourths respond correctly to an item they are asked to find at least one other student who answered differently than they did and discuss or debate the question. After discussions die down or start to turn to other topics, the instructor calls for a second, more informed vote. The second vote will often show dramatically improved results, sometimes with nearly complete agreement on the correct response. Specific implementations steps are described 
elsewhere (Duncan, 2007; Mazur, 2009; Prather \& Brissenden, 2009; Slater, 2013). More to the point, research from attitude surveys show that most students consider this class time well spent, believing that it helps them learn. This has been confirmed by research and studies have shown less expensive sets of colored flashcards work as effectively as electronic systems (Lasry 2008; Prather \& Brissenden, 2009).

Leveraging this assessment instructional approach, visual-assessments and tutorials (LoPresto, 2010b) were created for students to think-pair-share about. Rather than simply being shown pictures and/or diagrams, students are instructed to construct and/or examine pictures and/or diagrams related to the topics being studied. Topics that lend themselves to being studied this way are those that are more visual in nature, which includes many in introductory astronomy as well as other areas of science. This is similar to a pedagogy known as visual literacy tasks (Slater, 2010), as well as one called a picture tells a thousand words. (Keely \& Sneider, 2012).

Taken together, these two broad ideas about teaching - collaborative learning through lecture-tutorials and formative assessment-driven learning activities - serve as the context for this study of active learning in the domain of astronomy learning. To help the astronomy teaching community make informed decisions about the impact of various approaches, pre-test to posttest learning gains for students receiving instruction on introductory astronomy solar system topics through a combination of collaborative learner-centered activities and formative assessment activities were compared to the gains of students being taught the same topics by traditional lectures only.

\section{METHOD AND RESULTS}

To determine how much students learn from various active-learning teaching approaches compared to traditional approaches, instruction using lecture-tutorials was compared to instruction by traditional lectures with a pre-test, posttest research design (Slater, Slater, Heyer, \& Bailey, 2015a, p. 45). One hundred forty-four participants agreed to participate in the initial phases of the study. These student-participants were enrolled in one of several college-level, introductory astronomy survey courses taught at a large, public, open-enrollment, two-year associate's degree granting community college in the urban upper Midwest of the United States. The demographics matched those of the institution at large: $45 \%$ males and $55 \%$ females; $37 \%$ of students are classified as full-time; and a racial profile of 45\% Caucasian; 23\% Black; and 25\% unreported race. Most (72\%) of students are between 17 and 30 years of age, with an average age of 26 years. Although, the study focused on the teaching of solar system astronomy topics, the 16-week long course included all the topics usually covered in introductory astronomy. Most of the students were non-science majoring undergraduates.

Specific and purposeful precautions were taken to minimize instructor bias. Data was taken with students in sections taught by five different instructors and whether the instructors were going to be lecturing or using learner-centered techniques, discussions between instructors occurred to make sure that all the concepts to be assessed were being covered adequately. Also, when instructors taught multiple sections that were being assessed, some were taught with lecture and others were learner-centered. This was to assure that students surveyed were not all hearing lectures or receiving learner-centered instruction from the same instructor. Pertaining to data collected specifically for this paper; the corresponding author did teach several of the class sections using visual-assessments but none of the sections using lecture-tutorials.

\section{Study 1: Impact of Lecture-Tutorials on Solar System Formation}

To measure the content knowledge of student-participants, multiple-choice questions about the formation of the solar system were asked in a pre-test and post-test format. One hundred forty-four participants took the pre-test to establish the prior knowledge level as an incoming baseline to look for change.

After traditional instruction the same survey questions were given to a subset of $\mathrm{n}_{\text {lecture }}=49$ students that received a traditional lecture on the topic. Another separate group of students, $\mathrm{n}_{\mathrm{LT}}=72$, participated in both the traditional lecture and then completed a short lecture-tutorial activity covering the formation of the solar system. This research design is consistent with the multiple-measures research design done in earlier research on the effectiveness of lecturetutorials by Prather, Slater, and their colleagues (2005). 
Results for each are shown in Table 1 and in Figures 1 and 2. Table 1 shows percentage of correct responses on each item on the solar system formation pretest items for all students and the posttest results in each of the two groups as well as the averages and normalized gains. Normalized gain, $g=$ (posttest $\%$-pretest $\%) \div(100 \%$ - pretest $\%)$ (Hake 1998; Slater, Slater, Heyer, \& Bailey, 2015a, p. 45). It is important to notice in Table 1 and Figures 1 and 2 that students completing the lecture-tutorial had greater gains on all items compared to those receiving traditional lectures only. The $p$-value for a $t$-test comparing the number of correct and incorrect responses in each group for the seven (7) items was $p=0.00009$. For one comparing the gains for each group, $p=0.00034$.

Table 1. Pretest and posttest scores and normalized gains for students receiving lectures only and those doing both a lecture-tutorial and formative assessment activities on the same topic.

\begin{tabular}{|c|c|c|c|c|c|}
\hline & \multicolumn{3}{|c|}{$\begin{array}{c}\text { Percentage of students giving correct answers about } \\
\text { solar system formation }\end{array}$} & \multirow[b]{2}{*}{$\begin{array}{l}\text { Gain from lecture } \\
\text { alone }\end{array}$} & \multirow[b]{2}{*}{$\begin{array}{l}\text { Gain from lecture } \\
\text { and lecture-tutorial }\end{array}$} \\
\hline & Pretest & After lecture & $\begin{array}{l}\text { After lecture- } \\
\text { tutorial }\end{array}$ & & \\
\hline Item \# & $N=144$ & $n_{\text {lecture }}=49$ & $\mathrm{n}_{\mathrm{LT}}=72$ & & \\
\hline 1 & 69 & 80 & 83 & 0.35 & 0.47 \\
\hline 2 & 36 & 31 & 67 & -0.09 & 0.48 \\
\hline 3 & 69 & 67 & 86 & -0.07 & 0.55 \\
\hline 4 & 31 & 55 & 67 & 0.35 & 0.52 \\
\hline 5 & 15 & 12 & 64 & -0.03 & 0.58 \\
\hline 6 & 33 & 43 & 81 & 0.14 & 0.71 \\
\hline 7 & 47 & 55 & 64 & 0.16 & 0.32 \\
\hline Average & 42 & 49 & 73 & 0.12 & 0.52 \\
\hline Standard Error & \pm 7.6 & \pm 8.6 & \pm 3.7 & \pm 0.07 & \pm 0.044 \\
\hline
\end{tabular}

Figure 1. Percent of correct responses before (left) and after instruction on assessment items 1-7 on solar system formation by students receiving lectures only (middle) and those completing both a lecture-tutorial (right) and formative assessment activities on the topic.

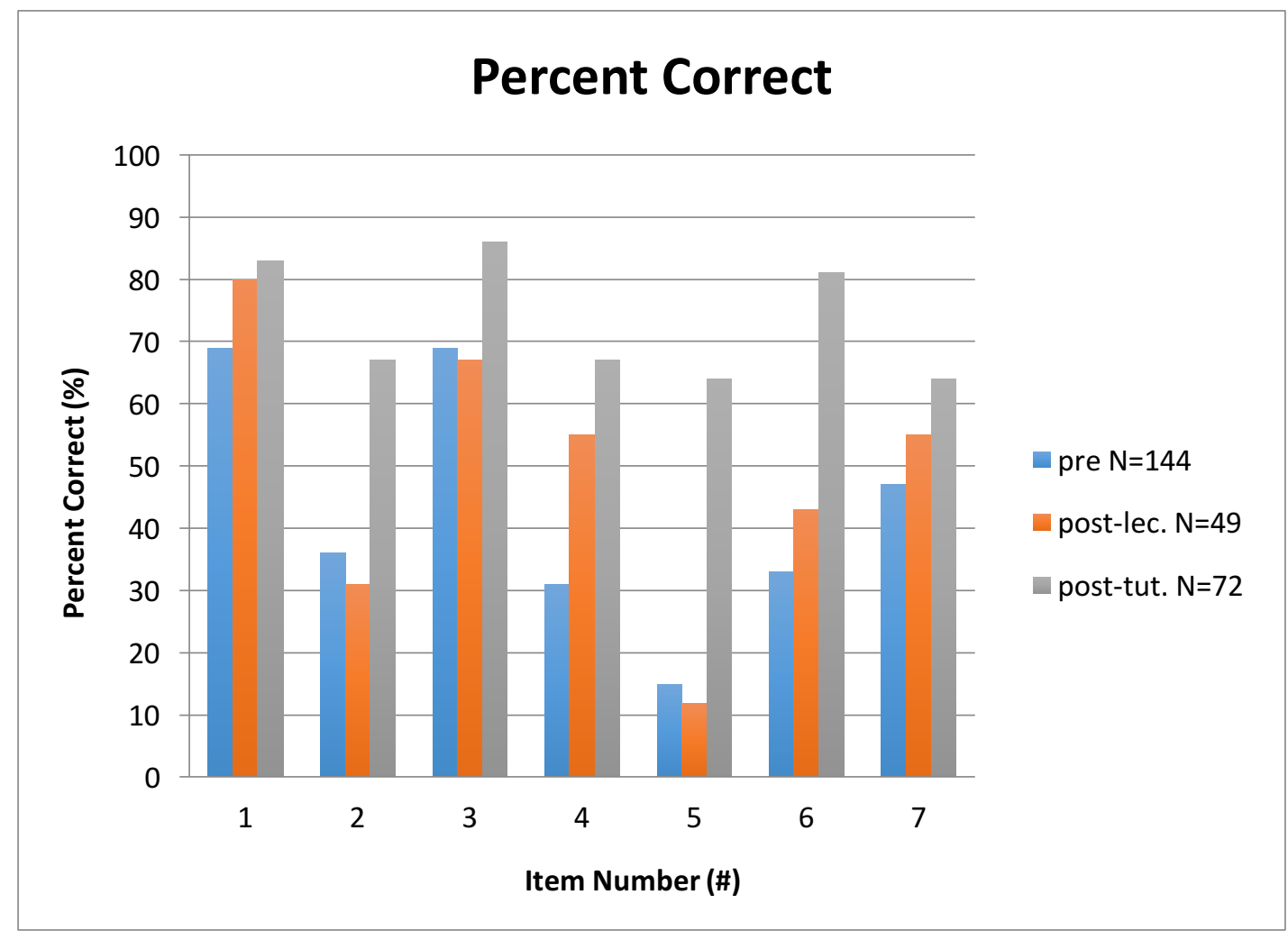


Figure 2. Normalized gains for assessment items 1-7 on solar system formation for students receiving lectures only (left) and those doing both a lecture-tutorial (right) and formative assessment activity on the topic.

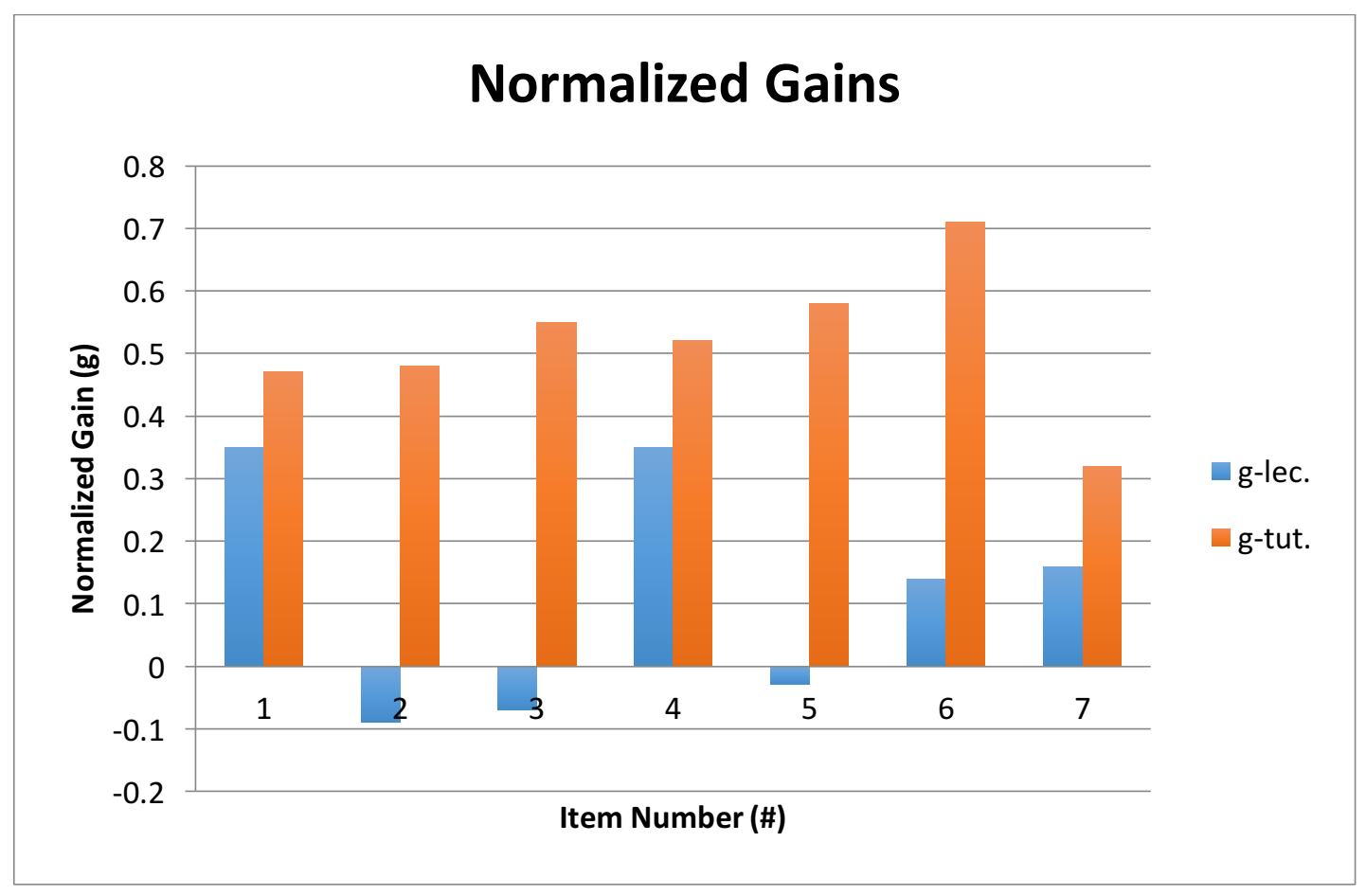

\section{Study 2: Impact of Lecture-Tutorial on Understanding Planetary Surfaces}

Similar to Study 1 described above, multiple-choice questions about solar system planetary surfaces were asked in a pre-test and post-test format to measure the content knowledge of all student-participants,. One hundred forty-four participants (the same 144 from study 1) completed these pre-test items to establish the prior knowledge level as an incoming baseline to look for change.

Table 2 and Figures 3 and 4 show the percentage of correct responses on the pretest and posttest and the average normalized gains for ten (10) items that were different from the seven items in the first phase of the study described above, but the students were the same. As before, students doing this particular lecture-tutorial (LoPresto, 2010a) had greater gains on all items compared those that received a lecture only. The $p$-value for a $t$-test comparing the number of correct and incorrect responses in each group for the ten (10) items was $p=0.00115$. For one comparing the gains for each group, $\mathrm{p}=0.00125$. 
Table 2. Pretest and posttest scores and normalized gains for students receiving lectures only and those doing both a lecture-tutorial and formative assessment on the topic.

\begin{tabular}{|c|c|c|c|c|c|}
\hline & \multicolumn{3}{|c|}{$\begin{array}{c}\text { Percentage of students giving correct answers about } \\
\text { planetary surfaces }\end{array}$} & \multirow[b]{2}{*}{$\begin{array}{l}\text { Gain from lecture } \\
\text { alone }\end{array}$} & \multirow[b]{2}{*}{$\begin{array}{l}\text { Gain from lecture } \\
\text { and lecture-tutoria }\end{array}$} \\
\hline & Pretest & After lecture & $\begin{array}{c}\text { After lecture- } \\
\text { tutorial }\end{array}$ & & \\
\hline Item \# & $\mathrm{N}=144$ & $n_{\text {lecture }}=49$ & $\mathbf{n}_{\mathrm{LT}}=72$ & & \\
\hline 1 & 65 & 69 & 92 & 0.14 & 0.77 \\
\hline 2 & 8 & 20 & 44 & 0.14 & 0.4 \\
\hline 3 & 30 & 22 & 42 & -0.11 & 0.17 \\
\hline 4 & 17 & 41 & 78 & 0.28 & 0.73 \\
\hline 5 & 15 & 29 & 38 & 0.16 & 0.26 \\
\hline 6 & 28 & 27 & 65 & -0.03 & 0.52 \\
\hline 7 & 17 & 8 & 25 & -0.11 & 0.09 \\
\hline 8 & 28 & 20 & 39 & -0.1 & 0.15 \\
\hline 9 & 53 & 71 & 82 & 0.4 & 0.62 \\
\hline 10 & 21 & 22 & 36 & 0.02 & 0.19 \\
\hline Average & 24.1 & 32.9 & 54.1 & 0.08 & 0.39 \\
\hline Standard Error & \pm 4.1 & \pm 6.7 & \pm 7.3 & \pm 0.05 & \pm 0.08 \\
\hline
\end{tabular}

Figure 3. Percent of correct responses before (left) and after instruction on assessment items 1-10 on the surface conditions of terrestrial planets for students receiving lectures only (middle) and those doing both a lecture-tutorial (right) and formative assessment activity on the topic.

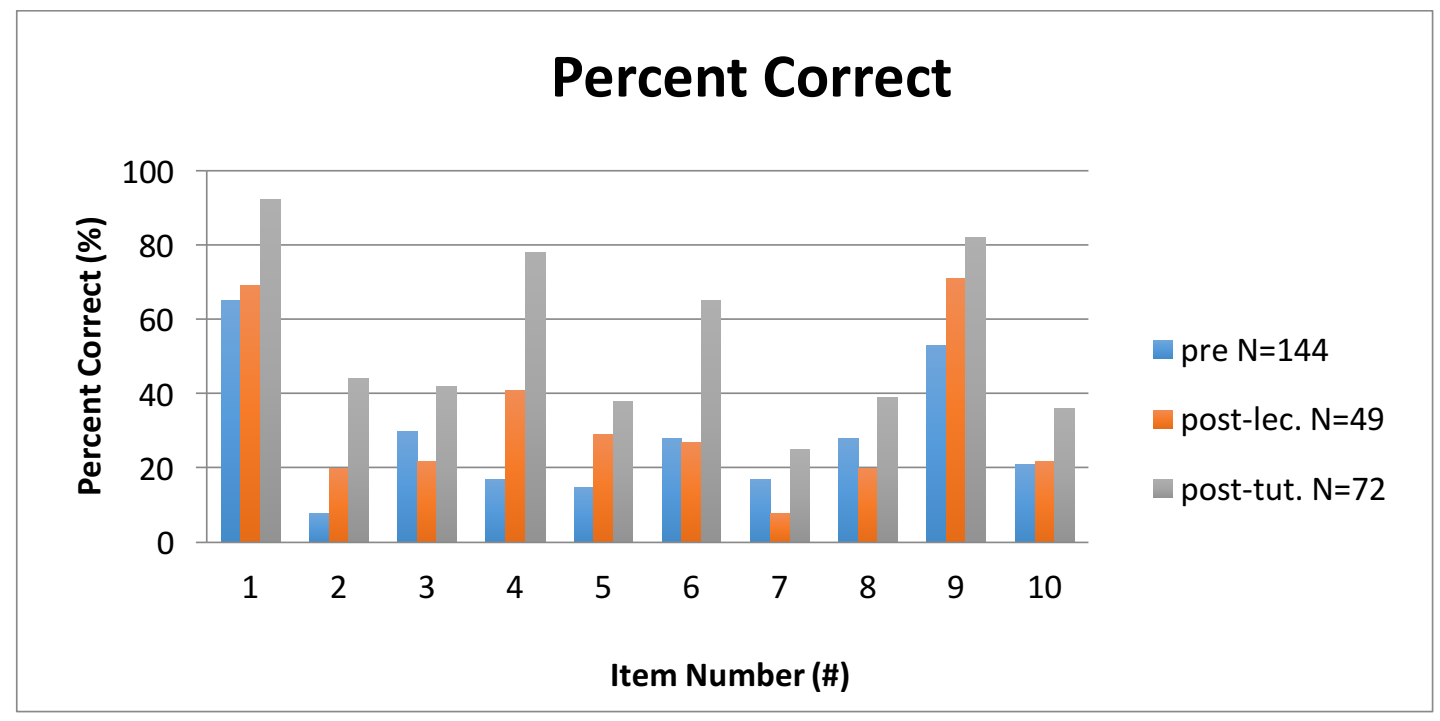


Figure 4. Normalized gains for assessment items 1-10 on the surface conditions of terrestrial planets for students receiving lectures only (left) and those doing both a lecture-tutorial (right) and formative assessment activity on the topic.

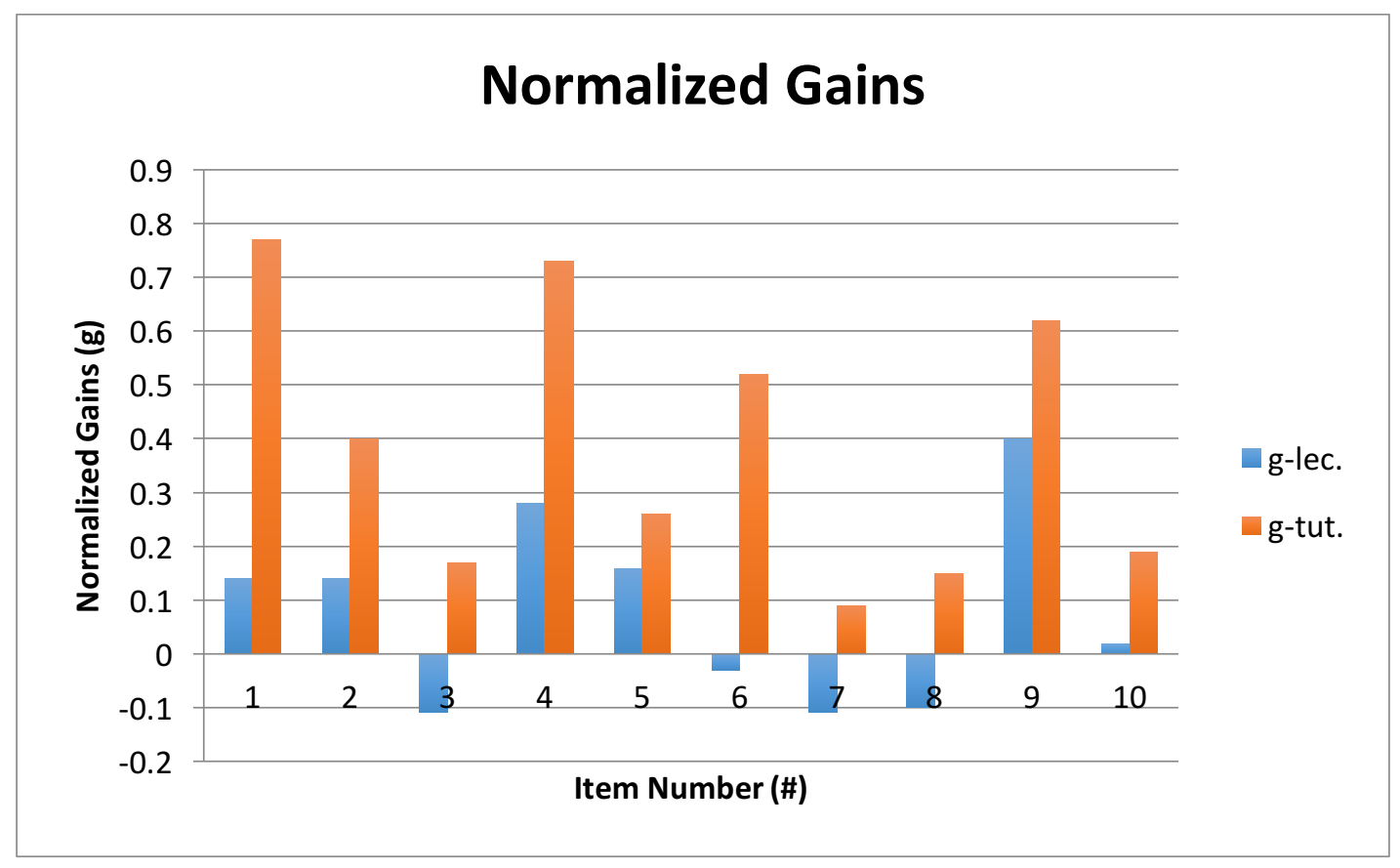

\section{Study 3: Impact of Visual-Assessments and Tutorials on Understanding Comets}

To better understand if student learning is the result of lecture-tutorial approach specifically, or if variations on active learning manifested as visual-assessments and tutorials have the same impact on student learning, 251 studentparticipants completed a pretest question shown in Figs. $7 \& 8$ before instruction on the subject of comets where they were instructed to draw the coma and tail in five places near the sun in a comet's eccentric orbit showing the relative sizes of the coma and tail and the orientation of the tail. After traditional lecture-based instruction, 105 students completed the visual assessment again. To investigate the impact of a visual-tutorial (LoPresto, 2012), in contrast to a lecture-tutorial, 136 students completed a visual-tutorial before taking the visual assessment again. To be clear, the traditional lectures introduced students to the diagram of a comet in its orbit that showed changes in the size and direction of the tail and the size of the coma, which is similar to those used in the visual-assessment and tutorial.

Table 3 and Figures 5 and 6 show pretest results for $\mathrm{N}=251$ students and posttest results for $\mathrm{n}_{\text {lecture }}=105$ students that received instruction on comets by traditional lectures only compared to $\mathrm{n}_{\mathrm{VA}}=136$ students that were taught the topics with the visual-tutorial. The lectures did include a diagram of a comet in its orbit that showed changes in the size and direction of the tail and the size of the coma. The $p$-values in Table 3 are the results of $2 \times 2$ contingency tests run on the number in each group answering each item correctly or incorrectly.

Item 1 is the relative sizes of the coma, item 2 are the relative lengths of the tail and item 3 is the directions of the tail. An example of a correct drawing for all three items is shown in Figure 7. Item 4 is the percentage of student drawings that reflected a common misconception, shown in Figure 8 that at all points in its orbit, a comet always travels head first and tail last. 
Table 3. Percentages of students correctly drawing: 1-the coma size; 2- the tail size; and 3- the tail direction of a comet before instruction and after instruction by lecture only and by the visual-tutorial. Item 4 is the percentage of student drawings that showed the misconception that a comet always travels head first and tail last at all points in its orbit before and after instruction by each method. The $p$-values are the result of 2 x 2 contingency tests run on the number in each group answering each item correctly or incorrectly.

\begin{tabular}{c|c|c|c|c|c|c}
\hline & \multicolumn{9}{|c|}{$\begin{array}{c}\text { Percentage of students giving correct } \\
\text { answers about comet orbits }\end{array}$} & \multicolumn{2}{|c}{} \\
\cline { 2 - 7 } & Pretest & $\begin{array}{c}\text { After } \\
\text { lecture }\end{array}$ & $\begin{array}{c}\text { After visual- } \\
\text { assessment }\end{array}$ & $\begin{array}{c}\text { Gain from visual - } \\
\text { assessment alone }\end{array}$ & $\begin{array}{c}\text { Gain from lecture and } \\
\text { visual-assessment }\end{array}$ \\
\hline Item & $\mathbf{N = 2 5 1}$ & $\mathbf{n}_{\text {lecture }}=\mathbf{1 0 5}$ & $\mathbf{n}_{\mathbf{V A}}=\mathbf{1 3 6}$ & g-lec. & g-VA. & $\boldsymbol{p}$-value \\
\hline $\mathbf{1}$ & 4.8 & 6.7 & 68.4 & 0.020 & 0.668 & 0.0001 \\
\hline $\mathbf{2}$ & 9.2 & 16.2 & 84.6 & 0.077 & 0.830 & 0.0001 \\
\hline $\mathbf{3}$ & 6.8 & 58 & 83.8 & 0.549 & & 0.0001 \\
\hline $\mathbf{4}$ & 66.1 & 22 & 7.4 & & & 0.0004 \\
\hline
\end{tabular}

Figure 5. Percentages of students correctly drawing: 1-the coma size; 2 - the tail size; and 3- the tail direction of a comet before (left) and after instruction in lecture only- sections (middle) and in sections doing the visual-tutorial (right). Item 4 is the percentage of student drawings that showed the misconception that a comet always travels head first and tail last at all points in its orbit before and after instruction by each method.

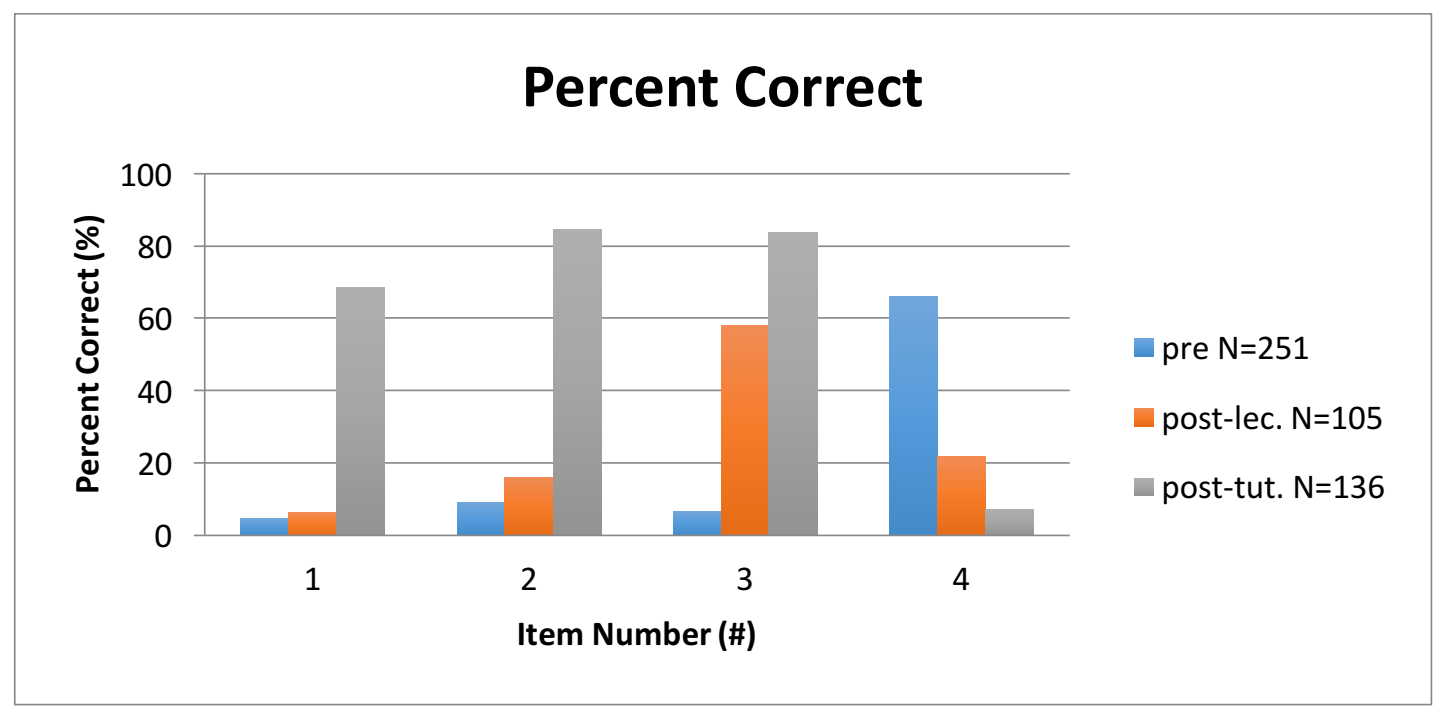


Figure 6. Normalized gains, g, on items 1-3 for students receiving lectures only (left), and section doing the visual-tutorial (right).

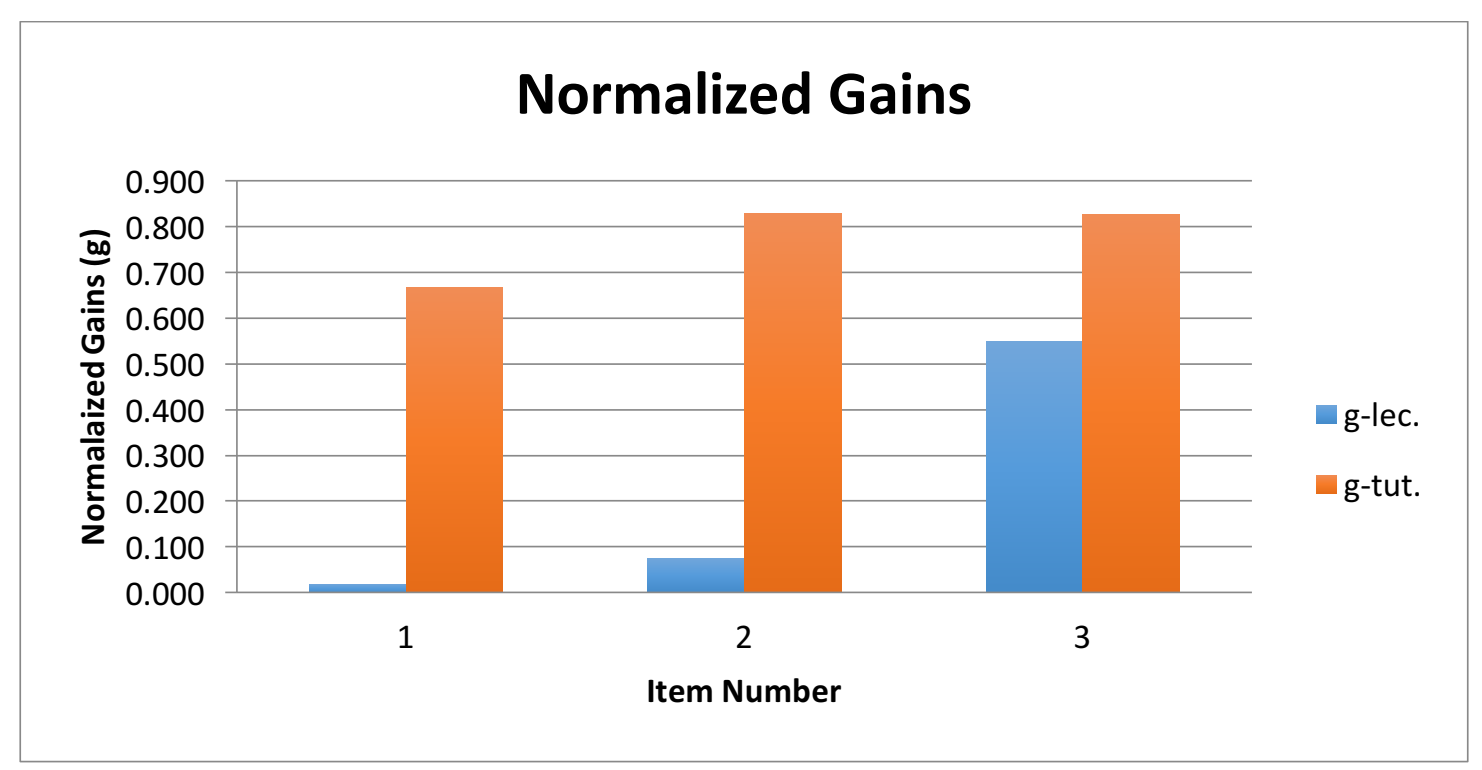

Figure 7. Student drawing showing the correct variations in size of the coma and tail as well as correct orientations of the tail at different points in a comet's orbit.

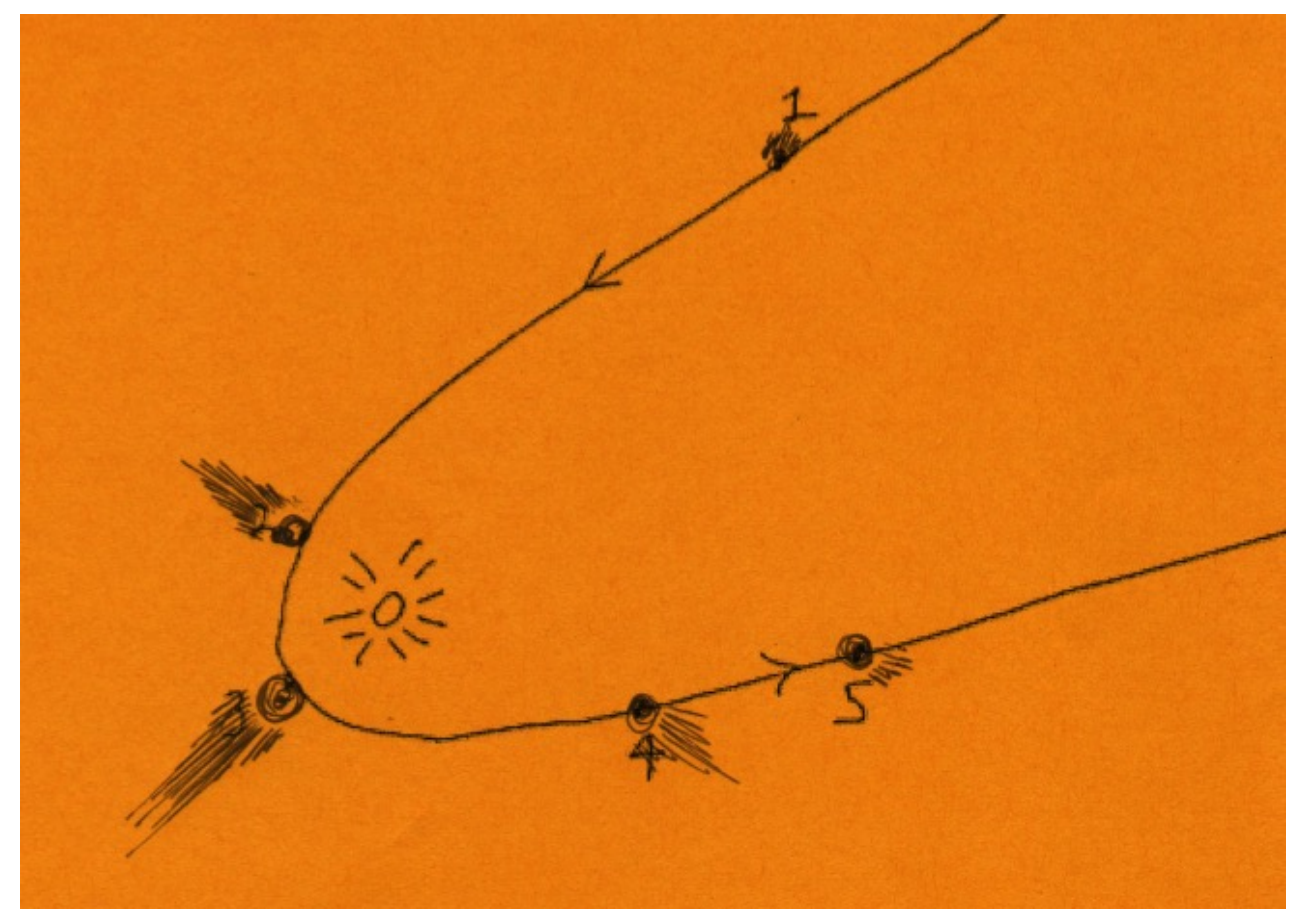


Figure 8. Student drawing showing the misconception that at all points in its orbit, a comet always travels head first and tail last.

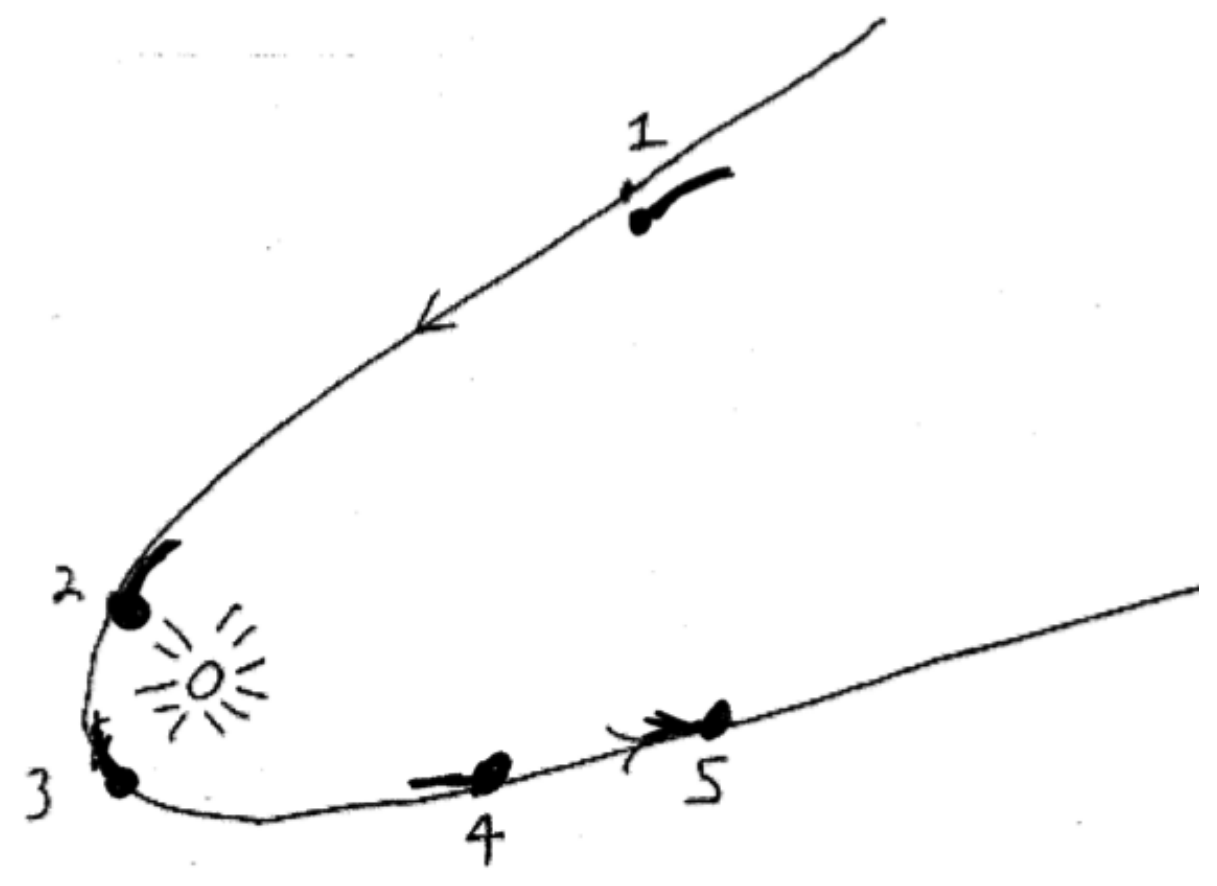

\section{Study 4: Impact of Visual-Assessment on Understanding Extra Solar Planet Detection}

Following the same motivation and study procedures as in Study 3 described above, students participated in a traditional lecture, or completed a visual-tutorial considering graphs of varying Doppler-shifts in the spectra of different sun-like stars caused by the presence of unseen planetary companions. Note that graphs appear somewhat different due to the presence of planets of differing mass, orbital period, orbital eccentricity as well as the presence of multiple planets.

As a pretest, 284 student-participants were asked to complete a diagnostic visual-assessment in which they were asked to match choices A-D as shown in Figures 9 and 10.

A massive planet in a close orbit

A massive planet in a far orbit

A lighter planet in a close orbit

A lighter planet in a far orbit. 
Figure 9. Part 1 of the visual-assessment used prior to and after instruction on detection of extra-solar planets.

A

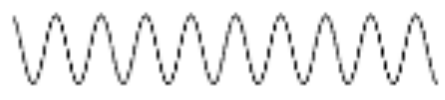

$\mathrm{C}$

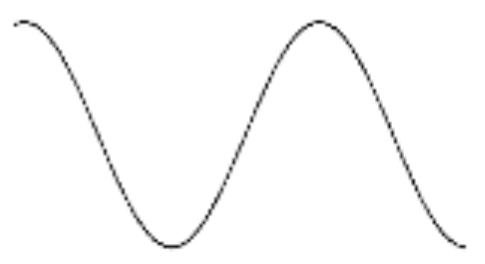

B

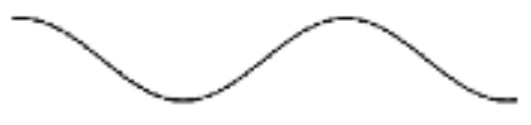

D

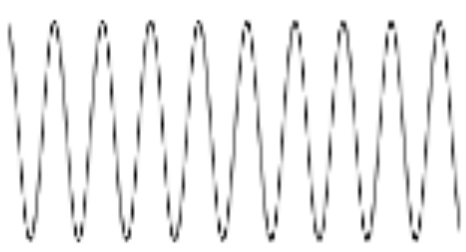

a planet in an eccentric orbit a multiple planet system a planet in a circular orbit.

Figure 10. Part 2 of the visual-assessment used prior to and after instruction on detection of extra-solar planets.

E

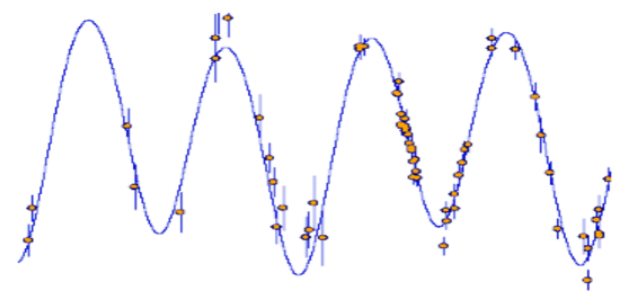

F

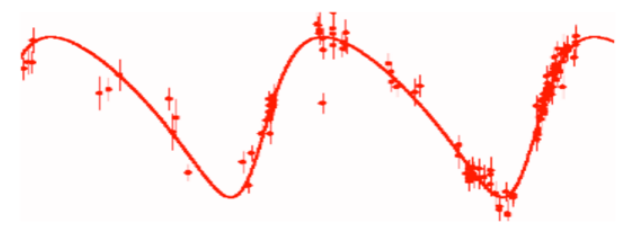

G

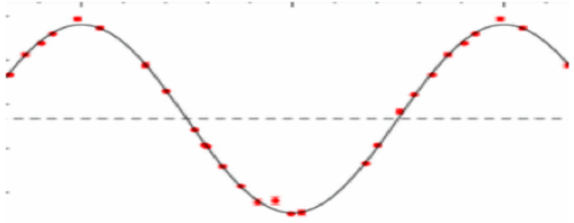


One hundred nine students were surveyed after they received in a traditional lecture on extra solar planet detection and 137 students were surveyed after they completed the visual-tutorial. The visual-tutorial on extra solar planet detection focused on analysis and construction of diagrams of how the waveforms of the plots of the changing Doppler-shifts in the light of a star are affected by planetary mass and orbital properties, including orbital eccentricity as well as the presence of multiple planets.

Pre-test results and posttest results for students receiving lectures and those completing the visual-tutorial are shown in Table 4 and Figures 11 and 12. The $p$-values in Table 4 are the result of $2 \times 2$ contingency tests run on the number in each group answering each item correctly or incorrectly.

Table 4. Percentages of students correctly identifying all 4 waveforms in Figure 9 (item 1), all 3 waveforms in Fig.10 (item 2 ) and identifying all 7 correctly (item 3 ) before and after instruction for students receiving lectures compared to those completing a visualtutorial on extra-solar planet detection. The $p$-values are the result of $2 \times 2$ contingency tests run on the number in each group answering each item correctly or incorrectly.

\begin{tabular}{|c|c|c|c|c|c|c|}
\hline & \multicolumn{3}{|c|}{$\begin{array}{c}\text { Percentage of students giving correct answers } \\
\text { about extra solar planet detection }\end{array}$} & \multirow[b]{2}{*}{$\begin{array}{c}\text { Gain from } \\
\text { visual - } \\
\text { assessment } \\
\text { alone } \\
\end{array}$} & \multirow[b]{2}{*}{$\begin{array}{c}\text { Gain from } \\
\text { lecture and } \\
\text { visual- } \\
\text { assessment }\end{array}$} & \multirow[b]{3}{*}{$p$-value } \\
\hline & Pretest & After lecture & $\begin{array}{l}\text { After visual- } \\
\text { assessment }\end{array}$ & & & \\
\hline item & $\mathrm{N}=\mathbf{2 5 1}$ & $n_{\text {lecture }}=105$ & $n_{V A}=136$ & g-lec. & g-VA. & \\
\hline 1 & 25.5 & 30.7 & 68.4 & 0.070 & 0.576 & 0.0001 \\
\hline 2 & 43.0 & 51.5 & 73.9 & 0.150 & 0.542 & 0.0003 \\
\hline 3 & 10.3 & 22.4 & 53.6 & 0.136 & 0.483 & 0.0001 \\
\hline
\end{tabular}

Figure 11. Percentages of students correctly identifying all 4 waveforms in Figure 9 in (item-1), all 3 waveforms in Figure 10 (item 2) and identifying all 7 correctly (item 3 ) on the pretest (left) for students receiving lectures (middle) and those completing the visual-tutorial activity (right) on extra-solar planet detection.

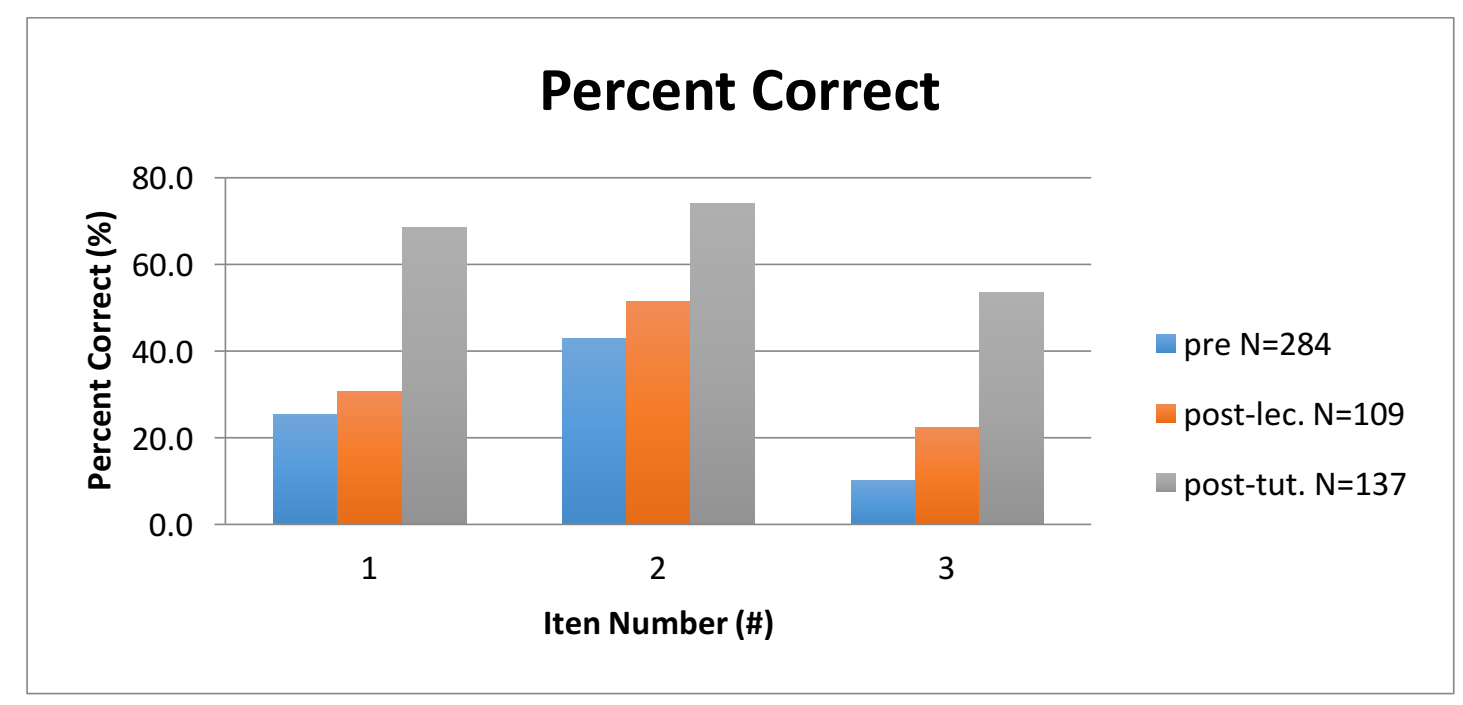


Figure 12. Normalized gains, $g$, on items 1-3 for students receiving lectures

(left), and students doing the visual-tutorial (right) on extra-solar planet detection.

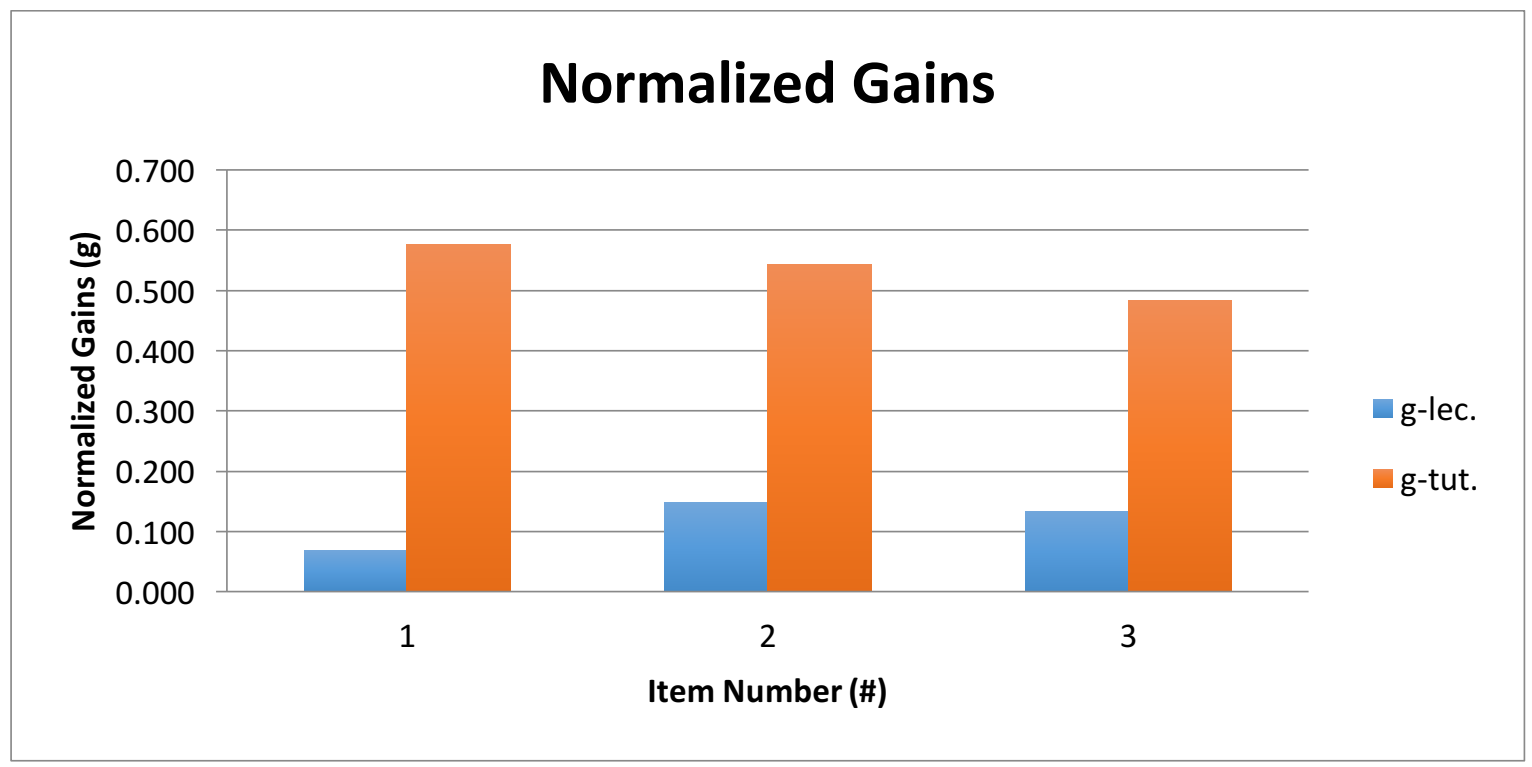

\section{Study 4: Student Attitudes about Active Learning}

At the end of the course, 264 students completed a Student Attitude Survey after those modeled by Slater, Slater, Heyer, and Bailey (2015b, p. 53). Table 5 shows the percentage of $\mathrm{N}=264$ students responding A-E on a Likert-scale item numbers 1-6. For an item 7 on whether they liked lectures or in-class activities better, about $30 \%$ of the N=264 students chose tutorials while $26 \%$ chose lectures, $38 \%$ chose that they liked them both, $4 \%$ said they liked neither and $2 \%$ were unsure.

Table 5. Percentage of students responding to A-E on each item of the post-course Student Attitude Survey.

\begin{tabular}{l|c|c|c|c|c}
\hline & A & B & C & D & E \\
\cline { 2 - 6 } & $\begin{array}{c}\text { Strongly } \\
\text { Agree }\end{array}$ & Agree & Neutral & Disagree & $\begin{array}{c}\text { Strongly } \\
\text { Disagree }\end{array}$ \\
\hline I like in-class activities & 46 & 33 & 15 & 3.4 & 3.0 \\
\hline I like lectures & 45 & 28 & 19 & 3.0 & 4.9 \\
\hline I learn from in-class activities & 55 & 27 & 11 & 2.3 & 4.9 \\
\hline I learn from lectures & 59 & 27 & 11 & 1.2 & 2.3 \\
\hline I like voting & 50 & 35 & 12 & 1.4 & 1.4 \\
\hline I learn when voting in class & 47 & 37 & 12 & 2.6 & 1.3 \\
\hline
\end{tabular}

The survey also included a space for student-supplied responses. Numerous positive comments about in-class activities were that they were "hands on," "forced you to participate" and "led to good discussions." Also that they "required thought," "made you think for yourself," "allowed you to learn step by step" and that "they make you check answers as you go." Although considered by some, "challenging" and/or "confusing," it was also stated that tutorials "help you remember," "gave understanding" and "were satisfying when completed."

Positive comments about classroom voting activities were that, like lecture-tutorials, activities "led to good discussions, that "they forced you to get involved which helped you learn better," and that they were good for review. There were comments that students liked them being used diagnostically, while others said they did not like them being used in that fashion. Some even said they were "fun" and/or "game-like."

There were far fewer negative comments, the most common being that in-class activities should be graded or that an answer-key should be given. Prather, Rudolph and Brissenden (2009) recommend neither of these options - reasoning 
that once the answers are circulated many students will just find and try to memorize answers, no longer actually working the tutorials causing them to lose their effectiveness as teaching tools. Several students also suggested that the in-class activities could be given as homework or given more class-time because people work at different paces was also mentioned as was that more background on a topic should be given before in-class activities were assigned and that they were "hard to learn from." One student indicated that they initially thought that the voting-based visualassessments were going to be ineffective, and was serendipitously surprised at the good discussions that resulted from their use. Another student described them as "annoying, but helpful." One wished that the questions would be the ones that would be on the tests.

More general comments about both pedagogies were that they were "both good methods," "fun, new ways to learn," "encouraged hands-on work" and "working together." Also that they were "useful for different learning styles" and were good because they helped students see the various topics in more than one way and "solidified the information." One student commented that "the combination of lectures and activities were a good-mix of great methods to help us learn."

A few students mentioned that although they could learn from lectures, seeing the material in different ways helped and they appreciated that others might have different learning styles than they did. One student commented that although they liked lectures, they were hard to focus on and it was good that other teaching methods were employed. Only a few students made a point of commenting specifically that they preferred lectures.

\section{DISCUSSION}

As professors struggle to decide precisely which of the active learning strategies they should adopt to improve teaching, the results of this study suggest that the specifics do not significantly matter. In this study, lecture-tutorial activities and visual-tutorials and assessment activities did equally well at improving student understanding.

Comparison of assessment results for both the lecture-tutorials and visual-assessments and tutorials' when compared to lectures show students experiencing greater learning gains when engaged in activities. All results were statistically significant and also consistent with previous research on the use of lecture-tutorials (Prather et al., 2005) and visualassessments and tutorials (LoPresto, 2010) and the more general premise that larger learning gains will result when students are actively engaged and interacting. (Chickering \& Gamson, 1999; Gokhale, 1995; Mazur, 1997; Hake, 1998; Bransford \& Brown, 2000; Weimer, 2002; Donovan \& Bransford, 2005; Lasry, 2008; Lasry, Mazur, \& Watkins 2008; Prather et al., 2008; Prather, Rudolph, \& Brissenden, 2009).

A possible reason for the success of instruction with lecture-tutorials in that they simultaneously incorporate most of the recommendations of How People Learn. Since they are designed to be done by students working in small collaborative learning groups, they are learner and community centered and being geared toward using facts to teach concepts rather than memorization makes them knowledge centered. Assessments being recommended both prior to and shortly after use makes them assessment-centered. The same seems to be true for visual-assessments and tutorials. Since the students do the work in groups, the instruction is clearly learner and community centered and the visualassessments are used both diagnostically and formatively so it is also assessment-centered. Completion of the activities requires the appropriate use of concepts and not memorization of facts, so lecture-tutorials and visual-assessments and tutorials are also knowledge-centered.

When considering students voting using a think-pair-share approach in this study, the effectiveness of classroom voting as a strategy for active and collaborative learning is well documented elsewhere and consistent with the data collected in this study adding weight to those conclusions (Green, 2003; Duncan, 2006, 2007; Lasry, 2008; Mazur, 2009; Prather \& Brissenden, 2009). However, student gains in this study were not due to them alone. In earlier trials to test the effectiveness of the tutorials, students receiving lectures were still out-gained by those doing tutorials even when classroom response was being used with both groups (LoPresto, 2010; LoPresto \& Murrell, 2010).

Moreover, the affective data summarized here showing most students appreciate active-learning approaches is consistent with other research done on student attitudes about the use of lecture-tutorials (Prather et al., 2005, Brogt, 2007) , and voting-based think-pair-share-style in-class learning activities (Mazur 1997; Prather \& Brissenden 2009). 
Based on the affective data reported here, there is little question that students believe that they learn from classroom response and enjoy when instructors use it, especially to review class material. Students also perceive instructors who use them as being willing to take class time to review, which is something students indicated that many teachers will not take the time to do despite the fact that students find very useful.

Data from attitude surveys does not show students having a strong preference for either lectures or more active pedagogies, nor that they perceive themselves as learning much better from one or the other. Their comments, however, offer insight as to why assessments showed students participating in active and collaborative learnercentered pedagogies achieving higher gains than those receiving lectures. The students referred to being challenged, forced to think for themselves and getting involved in group discussions as helping them learn. This reflects that what students think is helping them learn is actually doing things for themselves rather than be told about them and also working with others instead of alone. This is the very essence of active and collaborative learning, and all indications from the data presented here suggest that professors implementing active learning should see benefits both in terms of greater student achievement and enhanced student attitudes.

\section{ACKNOWLEDGEMENTS}

This work was supported in part by the NASA/JPL Center for Astronomy Education (CAE) at the University of Arizona as part of the Collaboration of Astronomy Teaching Scholars (CATS) project, Solar System Concept Inventory (SSCI) \& Solar System Lecture-Tutorials Project and a through a Post-Doctoral Fellowship in the University of Michigan Department of Astronomy funded by University's Third Century Initiative and NSF grant AST-1514835.

\section{AUTHOR INFORMATION}

Michael C. LoPresto, Ph.D. Dr. LoPresto has taught introductory physics and astronomy at Henry Ford College since 1990. He earned his $\mathrm{PhD}$, on which this portions of this paper is based, through the James Cook University Centre for Astronomy in Townsville Australia and has served as a Postdoctoral Research Fellow in the Department of Astronomy at the University of Michigan, where he is an adjunct research associate and lecturer Email: lopresto@hfcc.edu

Timothy F. Slater, Ph.D. Professor Slater holds the University of Wyoming Excellence in Higher Education Endowed Chair of Science Education and is a Senior Scientist at the CAPER Center for Astronomy \& Physics Education Research. Email: tslater@uwyo.edu

\section{REFERENCES}

Alexander, W. R. (2004). Assessment of teaching approaches in an introductory astronomy college classroom. Astronomy Education Review, 3(2), 178-186.

Bransford, J. D., Brown, A. L., \& Cocking, R. R. (1999). How people learn: Brain, mind, experience, and school. Washington, DC: National Academy Press. http://www.nap.edu/catalog/9853/

Bransford, J. D., \& Donovan, M. S. (Eds.). (2005). How students learn: history, mathematics, and science in the classroom. Washington, DC: National Academies Press. http://www.nap.edu/catalog/10126/

Brissenden, G., Slater, T. F., \& Mathieu, R. D. (2002). The role of assessment in the development of the college introductory astronomy course. Astronomy Education Review, 1(1), 1-24.

Brogt, E. (2007). A theoretical background on a successful implementation of lecture-tutorials. Astronomy Education Review, 6 (1), 50-58.

Bok, D. (2009). Our underachieving colleges: A candid look at how much students learn and why they should be learning more. Princeton University Press.

Bonwell, C. C., \& Eison, J. A. (1991). Active learning: creating excitement in the classroom. 1991 ASHE-ERIC higher education reports. ERIC Clearinghouse on Higher Education, The George Washington University, One Dupont Circle, Suite 630, Washington, DC 20036-1183. http://files.eric.ed.gov/fulltext/ED336049.pdf

Chickering, A. W., \& Gamson, Z. F. (1999). Development and adaptations of the seven principles for good practice in undergraduate education. New Directions for Teaching and Learning, 1999(80), 75-81.

Duncan, D. (2006). Clickers: A new teaching aid with exceptional promise. Astronomy Education Review, 5(1), 70-88.

Duncan, D. (2007). Clickers in the astronomy classroom. San Francisco, CA, Pearson. 
Fairweather, J. (2008). Linking evidence and promising practices in science, technology, engineering, and mathematics (STEM) undergraduate education. Board of Science Education, National Research Council, The National Academies, Washington, $D C$.

Gokhale, A. A. (1995). Collaborative learning enhances critical thinking. Journal of Technology Education, 7(1), 22-30.

Green, P. J. (2003). Peer instruction for astronomy. Upper Saddle River, NJ: Pearson Education.

Hake, R. R. (1998). Interactive-engagement versus traditional methods: A six-thousand-student survey of mechanic's test data for introductory physics courses. American Journal of Physics, 66(1), 64-74.

James, M. C., Barbieri, F., \& Garcia, P. (2008). What are they talking about? Lessons Learned from a Study of Peer Instruction. Astronomy Education Review, 7(1), 37-43.

Keeley, P., \& Sneider, C. I. (2012). Uncovering student ideas in astronomy: 45 formative assessment probes. Arlington, VA: National Science Teachers Association Press.

Kober, N. (2015). Reaching students: what research says about effective instruction in undergraduate science and engineering. Washington, DC: National Academies Press. http://www.nap.edu/catalog/18687/

Lasry, N. (2008). Clickers or flashcards: Is there really a difference? The Physics Teacher, 46(4), 242-244.

Lasry, N., Mazur, E., \& Watkins, J. (2008). Peer instruction: From Harvard to the two-year college. American Journal of Physics, 76(11), 1066-1069.

LoPresto, M. C. (2010a). Comparing a lecture with a tutorial in introductory astronomy. Physics Education, 45(2), $196-201$.

LoPresto, M. C. (2010b). Using visual assessments and tutorials to teach solar system concepts in introductory astronomy. Astronomy Education Review, 9(1), 1-12.

LoPresto, M. C. (2012). Comparing modern methods of active \& collaborative learning \& learner-centered teaching to traditional lectures. $\mathrm{PhD}$ thesis, James Cook University. http://researchonline.jcu.edu.au/31454/

LoPresto, M. C., \& Murrell, S. R. (2010). A comparative planetology activity. The Physics Teacher, 48(5), $296-299$.

Mazur, E. (1997). Peer Instruction: A User's Manual. Englewood Cliffs, NJ, Prentice Hall.

Mazur, E. (2009). Farewell, lecture. Science, 323(5910), 50-51.

NAP (2007). Rising above the gathering storm: energizing and employing America for a bright economic future. Washington, DC: National Academies Press. http://www.nap.edu/catalog/11463/

Nielsen, N. (2011). Promising practices in undergraduate science, technology, engineering, and mathematics education. Washington, DC: National Academies Press. http://www.nap.edu/catalog/13099/

Prather, E. E., \& Brissenden, G. (2009). Clickers as data gathering tools and students' attitudes, motivations, and beliefs on their use in this application. Astronomy Education Review, 8(1), 10 pages.

Prather, E. E., \& Brissenden, G. (2009). Lecture-Tutorials-How-To. Retrieved from: http://astronomy101.jpl.nasa.gov/teachingstrategies/teachingdetails/?StrategyID=9

Prather, E. E., Rudolph, A. L., Brissenden, G., \& Schlingman, W. M. (2009). A national study assessing the teaching and learning of introductory astronomy. Part I. The effect of interactive instruction. American Journal of Physics, 77(4), 320-330.

Prather, E. E., Rudolph, A. L., \& Brissenden, G. (2009). Teaching and learning astronomy in the 21st century. Physics Today, 62(10), 41-47.

Prather, E. E., Slater, T. F., Brissenden, G., Adams, J. P., \& Dostal, J. A. (2012). Lecture-tutorials for introductory astronomy. $3^{\text {rd }}$ Ed. San Francisco, CA: Pearson.

Prather, E. E., Slater, T. F., Adams, J. P., Bailey, J. M., Jones, L. V., \& Dostal, J. A. (2004). Research on a lecture-tutorial approach to teaching introductory astronomy for non-science majors. Astronomy Education Review, 3(2), 122-136.

Singer, S. R., Nielsen, N. R., \& Schweingruber, H. A. (Eds.). (2012). Discipline-based education research: understanding and improving learning in undergraduate science and engineering. Washington, DC: National Academies Press. http://www.nap.edu/catalog/13362/

Slater, S. J., Slater, T. F., Heyer, I., \& Bailey, J. M. (2015a). Conducting astronomy education research: an astronomer's guide, $2^{\text {nd }}$ Edition. Hilo, Hawai'i: Pono Publishing. ISBN: 1515025322

Slater, S. J., Slater, T. F., Heyer, I., \& Bailey, J. M. (2015b). Discipline-based education research: A scientist's guide, $2^{\text {nd }}$ Edition. Hilo, Hawai'i: Pono Publishing. ISBN: 1515024563

Slater, T. F. (2010). Engaging students' astronomical thinking with metacognitive visual literacy tasks. The Physics Teacher, 48(9), 618-619.

Slater, T. F. (2013, January). Educational theory underlying astronomy clicker questions \& peer instruction, from the AstroLrner.org blog, https://astronomyfacultylounge.wordpress.com/2013/01/02/educational-theory-underlyingastronomy-clicker-questions-peer-instruction/

Slater, T. F., \& Adams, J. P. (2003). Learner-centered astronomy teaching: Strategies for ASTRO 101. Upper Saddle River, NJ: Prentice Hall.

Weimer, M. (2002). Learner-centered teaching: Five key changes to practice. Boston: John Wiley \& Sons. 


\section{NOTES}

